\title{
"A REALIDADE OBEDECIA A UMA OUTRA ESCALA": REALISMO AFETIVO EM AZUL CORVO, DE ADRIANA LISBOA ${ }^{1}$
}

"REALITY OBEYED ANOTHER SCALE": AFFECTIVE REALISM IN CROW BLUE ${ }^{2}$, BY ADRIANA LISBOA

\author{
Renata Rocha Ribeiro \\ Universidade Federal de Goiás \\ Goiânia, GO - Brasil \\ ORCID 0000-0003-1714-3182
}

\section{Resumo}

$\mathrm{Na}$ contemporaneidade o realismo como forma e abordagem narrativas tem sido bastante comentado pela teoria e pela crítica. No contexto brasileiro, parte da crítica especializada, ao tentar delimitar o contemporâneo, destaca o realismo em relação direta com a superexposiçáo da violência, vista como um dos principais temas de hoje. Nesse sentido, expressōes como "brutalista" (BOSI, 2002) e "realismo feroz" (CANDIDO, 2011), por exemplo, perpassam as análises de obras que conjugam violência e realismo. Todavia, a despeito da profusão de narrativas que se constroem sobre esse binômio, a proposta do presente artigo não é associar o realismo à marginalidade ou à violência. Por meio da leitura do romance Azul Corvo, de Adriana Lisboa, publicado em 2010, pretendemos trabalhar com a experiência do que Schøllhammer identifica como "realismo afetivo" (2002, 2004, 2011, 2013).

Palavras-chave: Literatura Brasileira; Romance contemporâneo; Realismo; Realismo afetivo; Adriana Lisboa.

\section{Abstract}

In contemporaneity, realism as a narrative form and approach is being quite commented on by the theory and the critics. In the Brazilian context, some specialized critics, when trying to delimit the contemporary, highlight realism in direct relation to the super exposition

\section{Resumen}

En la contemporaneidad, el realismo como forma y abordaje narrativos ha sido muy difundido, tanto por la teoría como por la crítica. En el contexto brasileño, parte de la crítica especializada, al intentar delimitar lo contemporáneo, pone de relieve el realismo, relacionán-

1 Este artigo faz parte dos estudos iniciais que resultaram no projeto de pesquisa de pós-doutorado intitulado "Memórias da ditadura em romances de Adriana Lisboa e María Teresa Andruetto", desenvolvido na Universidade Federal de Minas Gerais, com o apoio do edital 09/2018 da CAPES/Fapeg.

2 Título do romance segundo tradução ao inglês de Alison Entrekin (LISBOA, 2014b). 
of violence, seen as one of the main themes of today. In that sense, expressions such as "brutalist" (BOSI, 2002) and "fierce realism" (CANDIDO, 2011), for example, brush the analyses of works that conjugate violence and realism. However, despite the profusion of narratives that are constructed upon this binomial, the proposition of this work is not to associate realism with marginality or violence. Through the reading of the novel Crow Blue, by Adriana Lisboa, published in 2010, we intend to work with the experience of what Schøllhammer identifies as "affective realism" (2002, 2004, 2011, 2013).

Keywords: Brazilian literature; Contemporary novel; Realism; Affective realism; Adriana Lisboa. dolo directamente con la sobrexposición de la violencia, tenida como uno de los principales temas de la actualidad. En ese sentido, expresiones como "brutalidad" (BOSI, 2002) y "realismo feroz" (CANDIDO, 2011), por ejemplo, pasan por el análisis de obras que conjugan violencia y realismo. A pesar de la profusión de narrativas que se construyen sobre ese binomio, la propuesta de este artículo no es asociar el realismo a la marginalidad o a la violencia. A partir de la lectura de la novela Azul corvo, de Adriana Lisboa, publicado en 2010, pretendemos trabajar con la experiencia de lo que Schøllhammer identifica como "realismo afectivo" (2002, 2004, 2011, 2013).

Palabras clave: Literatura brasileńa; Novela contemporánea; Realismo; Realismo afectivo; Adriana Lisboa.

Dentre as tendências contemporâneas da prosa de ficção brasileira apontadas pela crítica especializada, como a "fertilidade literária”, a "multiplicidade" (RESENDE, 2008, p. 16-17), a "pós-utopia” (CARNEIRO, 2005, p. 15-31), a relação com diversos sistemas semióticos e a "impureza" (BARBIERI, 2003, p. 15-21), que parecem já ter se tornado sedimentos desse território crítico, destaca-se o nó teórico da relação entre realidade e representação. Em outras palavras, a crítica vem observando muito de perto uma recorrência obsessiva na prosa de ficção brasileira contemporânea: o modo como o realismo tem se manifestado nos contos e romances.

Via de regra, ultimamente, o sentido de realismo tem sido associado à abordagem do tema da violência e da marginalidade. Alfredo Bosi caracterizou a dicção crua de Rubem Fonseca como "brutalista" (BOSI, 2002, p. 18); Antonio Candido cunhou a expressão "realismo feroz" (CANDIDO, 2011, p. 255) para se referir à tendência ultrarrealista do mesmo escritor. Beatriz Resende, ao comentar sobre a presença do tema da violência em narrativas hodiernas 
(como Cidade de Deus, de Paulo Lins, publicado em 1997), o destaca como uma das tendências atuais de bom alcance mercadológico.

Entretanto, apesar da profusão de obras e autores que percorrem o caminho apontado acima, a proposta do presente artigo não é explorar essa via. Por meio da leitura do romance Azul corvo, de Adriana Lisboa, que veio a público em 2010, pretendemos trabalhar com a experiência do que Karl Erik Schøllhammer identifica como "realismo afetivo". Optamos, neste texto, em dar destaque ao trabalho de Schøllhammer devido à observação de que, nos últimos anos, esse crítico dedicou seu pensamento em direção a expressóes desse realismo contemporâneo.

Talvez seja desnecessário dizer que as reflexóes e acepçóes sobre o realismo são diversas. Em um sentido mais amplo, o realismo é entendido como uma relação imediata entre representação e realidade. Nos estudos atuais, esse sentido amplo parece ser o mais corrente, mas também não se deixa de levar em conta o realismo como forma, como se vê no que Tânia Pellegrini considera, na narrativa brasileira da década de 1970, como o "retorno constante e cíclico do naturalismo como processo narrativo" (PELLEGRINI, 1996, p. 18-19, grifos nossos), ou como movimento/tendência literária, que é o que se realiza quando o Realismo do século XIX é colocado em perspectiva comparatista com o contemporâneo.

A contemporaneidade, em contraste com o Realismo do século XIX, se vê liberada do compromisso premente com a representação pautada em obedecer preceitos da verossimilhança. Observamos um retorno não apenas das manifestaçóes artísticas ao real ${ }^{3}$, mas também percebemos "modos" distintos de representação desse real na contemporaneidade.

Como "modos" de realismo na contemporaneidade, Schøllhammer identifica, por exemplo, o "hiper-realismo", a possibilidade de um "novo regionalismo" (SCHØLLHAMMER, 2011, p. 70), o "realismo do choque" (SCHØLLHAMMER, 2013, p. 162), o "realismo indexical" (SCHØLLHAMMER, 2013, p. 175), o "realismo performático” (SCHØLLHAMMER, 2013, p. 178). Entretanto,

3 Sobre a ideia de "retorno ao real", é interessante recorrer ao ensaio "The return of the real" (1996), de Hal Foster. No Brasil, foi traduzido como "O retorno ao real" e publicado na revista Concinnitas, ano 6, v. 1, n. 8, jul. 2005. 
na produção do crítico se destaca a noção de "realismo afetivo", que vem sendo elaborada ao longo de seu pensamento sobre a literatura brasileira contemporânea. Assim, em seguida, será realizada uma abordagem da trajetória desse conceito e sua vinculaçáo com o romance Azul corvo.

\section{Azul corvo e o realismo afetivo}

A primeira edição de $A z u l$ corvo foi publicada em 2010, pela Editora Rocco. Quinto romance de Adriana Lisboa, foi finalista do Prêmio São Paulo de Literatura de 2011 na categoria Melhor Livro do Ano, vencido por Rubens Figueiredo com Passageiro do fim do dia. A narrativa, em primeira pessoa, trata da rememoraçáo da infância e da adolescência de Evangelina, que está com 22 anos durante o presente da enunciação. Vanja, como é conhecida, nasce de mãe brasileira nos Estados Unidos, vai ao Rio de Janeiro ainda bebê, onde fica até a morte da mãe, Suzana. Um ano depois da morte de Suzana, com 13 anos, Vanja decide voltar aos Estados Unidos em busca de seu pai biológico, Daniel, de quem não tem notícias. Para isso, fica na casa de Fernando, em Lakewood, Colorado. Fernando é ex-guerrilheiro da Guerrilha do Araguaia e ex-marido de Suzana, um sobrevivente da ditadura. Aí também Vanja inicia um forte vínculo de amizade com Carlos, filho de imigrantes ilegais salvadorenhos. Os três, em três etapas distintas de suas vidas - Vanja (adolescente), Fernando (adulto) e Carlos (criança) -, passam por momentos de transformação e identificação, formando uma espécie de família sem laços consanguíneos. A princípio, entre outras coisas, Vanja observa o espaço para onde se deslocou. Ela compara, a todo momento, os ambientes e, sobre o novo espaço, reflete: "Foi a primeira vez na vida que me dei conta do tamanho relativo das coisas" (LISBOA, 2014a, p. 28). É nesse contexto de redimensionamento que Evangelina afirma que a realidade, ali, obedecia a uma outra escala. A representação daquela realidade, diante de seus olhos, aponta para uma representaçáo antes desconhecida e que será, com o tempo e o contato com Fernando e Carlos, principalmente, assimilada por ela. No contexto desta análise, é interessante observar o diálogo desse redimensionamento, da exis- 
tência de outras escalas, com os diferentes modos de representação do real na contemporaneidade.

Algumas das análises do romance, publicadas em revistas especializadas e produtos de pesquisas de pós-graduaçáo, tratam das questóes centrais depreendidas dele e que também săo capitais na narrativa brasileira contemporânea: os deslocamentos geográfico e íntimo; o lugar ou o não-lugar do migrante; o sentimento de pertença; o protagonismo feminino; a memória e a identidade. A partir de um breve apanhado crítico , percebe-se que a questáo do realismo em $\mathrm{Azul}$ corvo é tocada, mas náo verticalizada, por meio dos temas abordados nos estudos elencados. É a proposta, portanto, deste texto, colocar em diálogo o romance de Lisboa com essa tendência realista que, como se viu, é tâo profícua nos dias de hoje, e mais especificamente em contato com o realismo afetivo.

A denominação "realismo afetivo" parece ter sido apontada por Schøllhammer pela primeira vez em "À procura de um novo realismo: teses sobre a realidade em texto e imagem hoje", de 2002. O autor inicia seu ensaio afirmando que há uma tese recorrente de que a pós-modernidade é marcada por um questionamento da realidade. Caberia, então, perguntar qual o lugar da realidade, do realismo e do real na literatura hodierna.

O Modernismo do início do século XX outorgou, na visão do crítico, uma negaçăo da representaçăo mimética comum ao Realismo do século XIX, o que significaria, contraditoriamente, uma afirmaçáo dessa mesma possibilidade realista tradicional. A partir desse panorama, Schøllhammer considera que, na evolução das formas híbridas do Modernismo, surge uma antítese oriunda de qualidades materiais e estéticas. Nos últimos anos,

4 A título de exemplo, há os seguintes trabalhos publicados sobre $A z u l$ corvo em periódicos científicos: "A memória, seus fios e tramas: dois livros de Adriana Lisboa - Os fios da memória e Azul corvo", de Elis Crokidakis Castro (CASTRO, 2011); "A representação da identidade feminina no mundo globalizado do século XXI: uma leitura de Azul corvo de Adriana Lisboa", de Wilma dos Santos Coqueiro (COQUEIRO, 2013); "Deslocamentos urbanos na literatura brasileira contemporânea", de Regina Dalcastagnè (DALCASTAGNÉ, 2014); "Romance e poesia em Azul corvo (2010), de Adriana Lisboa", de Noraci Braucks e Leoné Barzotto (BRAUCKS; BARZOTTO, 2015) e "Modos de transmissão intergeracional em romances da literatura brasileira atual", de Zilá Bernd e Tanira Soares (BERND; SOARES, 2016). 
[...] estes efeitos sensuais alcançaram extremos de concretude, que nos permitem falar de um novo "realismo afetivo". Nesta perspectiva é possível analisar a literatura e a arte contemporâneas como expressão de uma estratégia alternativa de representaçáo, em que a tendência experimental modernista de criar formas heterogêneas e híbridas entre diversos regimes expressivos [...] visa a ressaltar uma concretude afetiva do signo até o limite de sua representabilidade (SCHØLLHAMMER, 2002, p. 78, grifos nossos).

Nesse momento cabe uma pausa para comentar sobre a acepção de "sensualidade", bem como sobre a raiz da ideia de "afeto" que acreditamos estar presente no texto de Schøllhammer. Comumente, apenas atentamos para a percepçáo de sensualidade como sendo o despertar do desejo sexual. Entretanto, aqui entendemos o termo não apenas por essa via, mas também pelo uso mais amplo do termo, que é o de ser algo relativo aos sentidos, tudo aquilo que, de alguma forma, desperta ou atrai os sentidos, algo que podemos verificar em certos fundamentos da psicanálise. Explicitamente, no ensaio "Realismo afetivo: evocar realidade além da representação", que será comentado adiante, percebemos que Schøllhammer buscou seu embasamento sobre a afetividade em alguns filósofos, como Mario Perniola (que cita Jacques Lacan), Gilles Deleuze e Félix Guattari. Inferimos que a estética do afeto se fundamenta em conceitos da psicanálise. Em primeira instância, a palavra "afetivo" deriva do verbo "afetar", que significa, entre outras coisas, "atingir". Logo, "afetivo" diria respeito a tudo aquilo que "atinge" algo ou alguém, positiva ou negativamente. O próprio Schøllhammer, em entrevista ao jornal $O$ Globo, assentiu que o realismo afetivo "[...] procura dar conta do que a escrita faz ao encontro [de um] objeto. Sublinha, na ficção, os elementos afetados pelo conteúdo, analisando como, simultaneamente, afeta a realidade que absorve em sua própria expressão" (SCHØLLHAMMER, 2014, grifos nossos). Logo, há uma espécie de jogo entre a escrita ficcional, seu objeto e a realidade, interna e externa à obra. Nesse jogo, esses elementos afetam uns aos outros simultaneamente, gerando efeitos que também afetam, em certo nível, o leitor. 
Em segundo lugar, "afetivo" deriva do substantivo "afeto", e é nesse sentido que buscamos o vocabulário psicanalítico. Segundo Jean Laplanche e Jean-Bertrand Pontalis, o afeto é um "[...] termo que a psicanálise tomou emprestado da terminologia psicológica alemã e que exprime qualquer estado afetivo, penoso ou desagradável, vago ou qualificado, quer se apresente sob a forma de uma descarga maciça, quer como tonalidade geral.”' (LAPLANCHE; PONTALIS, 2004, p. 11).

De acordo com Antonio Imbasciati, psicanalista italiano e professor de Psicologia, o que

[...] denominamos com a palavra afeto pode referir-se ao que nos é dado vivenciar conscientemente em certas circunstâncias, isto é, um estado subjetivo que "sentimos", mas pode também se referir àquilo que não se sente de modo direto, mas se entrevê ou se infere no comportamento alheio e, menos facilmente, no nosso (IMBASCIATI, 1998, p. 14).

Dessa forma, o afeto pode ser uma experiência consciente, um sentimento, mas também pode ser uma inferência do comportamento de alguém observada na resposta de outro. Para desfazer a possível confusão entre as duas possibilidades, Imbasciati (1998, p. 14-15) explica que, no primeiro caso, é melhor usar o termo sentimento, mesmo com a sombra da ideia de inconsciência, e designar a "afeto" um sentido mais amplo, o que pode inclusive ser retirado da etimologia do termo: "[...] afeto, particípio passado do verbo afficere, parece indicar claramente o caráter passivo da experiência subjetiva em questáo, ou bem o fato de que esta foge ao controle das nossas intençóes e dos nossos desejos" (IMBASCIATI, 1998, p. 14-15). O afeto, então, nessa perspectiva, é uma experiência subjetiva não-controlada pela vontade do indivíduo. Daí o avizinhamento, ainda na visão de Imbasciati, com termos como "emoção" e "paixão", e como

5 A edição consultada é argentina e a tradução feita é nossa. No original: "Palabra tomada por el psicoanálisis de la terminología psicológica alemana y que designa todo estado afectivo, penoso o agradable, vago o preciso, ya se presente en forma de una descarga masiva, ya como una tonalidad general." 
esses estados afetam o indivíduo, independente de seu desejo ou de sua percepção.

A partir dessas informaçóes é que reiteramos a ideia de que Schøllhammer teria buscado parte da gênese do conceito de realismo afetivo na psicanálise. Em "Os novos realismos na arte e na cultura contemporâneas", de 2004, o autor retoma o termo ao discutir, dentre outros pontos, a questáo ética na arte em tempos de extrema exposição midiática. Para o crítico, enquanto a literatura engajada de 1970 comprometia integralmente sua representaçáo com o panorama sociopolítico do país, "[...] as novas formas passam por um questionamento das possibilidades representativas num contexto cultural predominantemente midiático" (SCHØLLHAMMER, 2004, p. 219). Esse tipo de cultura midiática está presente, por exemplo, em Azul corvo, na medida em que apresenta referências da cultura pop e da transcrição do discurso da internet, em diálogo com referências culturais/literárias mais "eruditas", bem como de personagens e eventos históricos.

Schøllhammer também comenta que há, na contemporaneidade, um deslocamento em relação à tradição realista: a literatura busca hoje novas formas de experiência estética e se preocupa com o compromisso de testemunhar e denunciar a realidade, mas não nos moldes do que aconteceu em 1970, por exemplo. Narrativas como $O$ que é isso, companheiro? (1979), de Fernando Gabeira, foram produzidas "de dentro" de um contexto ditatorial e refletem uma postura que a crítica identificou como "não-alienada" ou "de resistência" ${ }^{\circ}$, em oposição ao que se convencionou chamar de "literatura intimista". Já Azul corvo também demonstra uma preocupação com questóes político-sociais, mas não com um olhar denunciador "de dentro" ou com um sentimento de literatura empenhada ${ }^{7}$, na medida em que explora esse tema histórico caríssimo à contemporaneidade brasileira de outra perspectiva: um olhar do presente sobre o fato já passado.

6 A título de exemplificação, citamos novamente o texto de Pellegrini, "Uma área de sombra", em que a autora comenta sobre a polêmica de a literatura ter de exprimir seu presente histórico em regimes de exceção, como foi o caso de várias narrativas da década de 1970.

7 Nos termos de Antonio Candido (1997) nos textos iniciais de Formação da literatura brasileira. 
Ainda no referido ensaio, Schøllhammer, ao se dirigir à questáo da ética na arte, contrasta o conceito de realismo afetivo com a estética do efeito e o realismo histórico (SCHØLLHAMMER, 2004, p. 226). Nessa esteira, o realismo afetivo, ao contrário do realismo tradicional, náo espera causar efeito por meio do espetáculo ou do escândalo. Aqui, o crítico adiciona mais uma camada ao entendimento de afeto: um estímulo da imaginação que liga um posicionamento ético a uma determinada estética. Assim, o realismo afetivo, por meio de efeitos de realidade sensuais, sensitivos, chegam a um uso de concretude extrema. É isso que quer se observar no romance Azul corvo: Evangelina, por meio do uso de objetos e seres concretos consegue atingir uma estética do afeto, por afetar a si própria, sua narrativa e também a sensibilidade do leitor. Nas palavras de Schøllhammer, a questấo agora é "como me sinto em relação a isso?", não mais "o que é isso?” (SCHØLLHAMMER, 2004, p. 219).

Em "O realismo de novo", de 2011, Schøllhammer reafirma a dimensão de um outro tipo de realismo: sua "[...] realidade não se apoia na verossimilhança da descrição representativa, mas no efeito estético da leitura, que visa a envolver o leitor afetivamente na realidade da narrativa." (SCHØLLHAMMER, 2011, p. 59, grifos nossos). O que está em jogo aqui é pensar sobre esse efeito estético de envolvimento entre obra e leitor, não necessariamente numa correspondência entre obra e expectativa emocional do leitor.

Já em "Realismo afetivo: evocar realidade além da representação"s, Schøllhammer continua sua comprovação da "fome de realidade" (SCHØLLHAMMER, 2013, p. 155) típica da contemporaneidade, que se manifesta em diversos níveis. Nesse ensaio, o crítico percorre uma trajetória pelo realismo e suas concepçóes, para daí comentar sobre o "realismo de choque", o "realismo afetivo", o "realismo indexical" e o "realismo performático". O crítico conclui que tais "modos" de manifestação de realismo na contemporaneidade não se dissociam, mas estáo ligados de alguma forma. $\mathrm{O}$ choque se

8 Esse texto havia sido publicado anteriormente no dossiê "Realismo e realidade" do n. 39 da revista Estudos de Literatura Brasileira Contemporânea, em 2012. Preferimos citar a versão do mesmo texto em capítulo de livro, de 2013, para não contrastar com o outro texto de 2012 do mesmo autor. 
conectaria ao afeto, que por sua vez também se une ao índice e à performance.

Schøllhammer continua sua abordagem afirmando que é fundamental, nesse contexto, entender que "[...] os afetos operam por meio de singularidades afirmativas e se realizam em subjetividades e intersubjetividades dinâmicas. $\mathrm{Na}$ experiência afetiva a obra de arte torna-se real com a potência de um evento que envolve o sujeito sensivelmente no desdobramento de sua realização no mundo" (SCHØLLHAMMER, 2013, p. 171-172). Entendemos, por conseguinte, que em $A z u l$ corvo a trajetória narrada por Evangelina em sua busca identitária é afetiva, por se realizar num percurso subjetivo e intersubjetivo, ou seja, na sua relação consigo mesma e com os outros, especialmente Fernando e Carlos. A dinamicidade se manifesta de maneira explícita quando há o deslocamento geográfico, mas também de forma implícita por meio do deslocamento íntimo. Evangelina não se sente desajustada no Rio de Janeiro, ela inclusive se identifica com o mar, demonstrando uma espécie de vocação aquática, numa dimensão afetiva, que vai inclusive apontar para o próprio título do romance (as "conchas azul corvo" do poema "The fish", de Marianne Moore). Todavia, ela sente a necessidade de se mover espacialmente e interiormente para dar conta de suas origens, para buscar sua referência masculina, uma vez que havia sido criada apenas pela mãe e não tivera figura paterna. Ao buscar - e encontrar - o pai biológico, percebe-se que a identificação com a ascendência masculina não se dará com ele. Evangelina e Daniel se conhecem, mantêm contato à distância, mas é em Fernando que a menina encontrará um pai. Essa certeza ela externa explicitamente nas últimas páginas do romance, aproximadamente um ano após a morte de Fernando, quando imagina a mudança de um único detalhe em sua vida:

Seria assim a minha versão:

[...] Fernando dirigiu muito mais do que as seis horas habituais entre uma cidade e outra na autoestrada I-25. Havia neve e gelo na pista. [...]

Quando chegou em Albuquerque eu dormia em meu quarto algum sono de sonhos pequenos, sonhos do tamanho da minha vida, que cabiam (que cabia) com sobras entre as grades do berço. Ele e minha mãe se abraçaram 
com a força da falta que sentiam um do outro. Ele foi para a cama com ela. Mais tarde, no meio da madrugada, ela preparou uma sopa e os dois sentaram diante da árvore de Natal para tomar a sopa.

Era para ser definitivo. E foi. (LISBOA, 2014a, p. 297298)

Esse "único detalhe", na verdade, mudaria toda a vida de Evangelina, pois se Fernando tivesse ficado na noite em que Suzana o chamou, se Suzana tivesse saído de seu padrão de abandonar pessoas e retomado o relacionamento que rompera, a menina teria tido um pai desde sempre.

Em seu conceito, Schøllhammer também afirma que, na estética do realismo afetivo, as fronteiras entre realidade e representação são ressaltadas, bem como a relação entre "o sujeito autoral e as subjetividades envolvidas na realização da obra." (SCHØLLHAMMER, 2013, p. 172). No caso de Azul corvo, é interessante observar como certos índices de realidade se fazem presentes inclusive pela relaçáo entre sujeito autoral e subjetividades envolvidas na e dentro da obra. Em entrevistas, Lisboa demonstra ter vivenciado a questão do deslocamento geográfico, tendo habitado várias cidades do mundo e morando atualmente nos Estados Unidos, que é o país para onde Evangelina se desloca, como já mostrado anteriormente. A indicação, inclusive, dos nomes de ruas e logradouros dos Estados Unidos, especialmente na viagem empreendida por Vanja, Fernando e Carlos em busca de pistas de Daniel, é muito precisa, sendo possível acompanhar os trajetos feitos por eles em aplicativos de mapas. A escritora também admite que o fato de Fernando ter participado da Guerrilha do Araguaia adveio da lacuna escolar em torno desse tema histórico, uma curiosidade da época em que era estudante. Isso aparece em $\mathrm{Azul}$ corvo, quando Evangelina demonstra que esse assunto era desprezado quando ia à escola no Rio de Janeiro.

Para Schøllhammer, na prosa de ficção contemporânea, o impacto afetivo é "[...] consequência de uma redução radical do descritivo, de uma subtração na estrutura narrativa da construção sintática de ação e da preeminência da oralidade contundente do discurso à procura do impacto cruel da palavra-corpo" (SCHØLLHAMMER, 
2013, p. 173). Ademais, o afeto, via leitura de Deleuze e Guattari, é "a transformação sensível em reação a certa situação, coisa ou evento." (SCHØLLHAMMER, 2013, p. 173). Em Azul corvo não se percebe uma torrente descritiva. A linguagem poetizada da autora acaba por tornar substantiva sua prosa. De certa forma, isso contribui também para uma sintaxe de ação mais enxuta. As descriçóes são feitas por meio de imagens impactantes, que em número reduzido de palavras já dáo conta de um todo. Observemos o seguinte exemplo, retirado do mesmo momento de reflexáo de Evangelina sobre a relatividade do tamanho das coisas:

Foi a primeira vez na vida que me dei conta do tamanho relativo das coisas. Tudo ficava pequeno naquele lugar. Até mesmo quando Fernando me levou para passear nas áreas ricas dos subúrbios ao sul de Denver. As casas imensas de dois, três andares eram pintadas em cores neutras e existiam plácidas e sonolentas feito bolos expostos no balcão de uma imensa confeitaria. Depois de algum tempo aquilo me pareceu meio perigoso, um pesadelo recorrente onde nada acontecesse de fato, mas onde houvesse uma promessa do macabro na quietude do ar, na ausência de gente andando pela rua, no conformismo dos gramados que eram como sorrisos falsos, nos arbustos em forma de bolota, domados, circenses. (LISBOA, 2014a, p. 28-29)

Aqui, Evangelina descreve a área nobre dos subúrbios de Denver. Para atingir a atmosfera artificial que aquele lugar transparecia à narradora, ela utiliza comparaçóes e metáforas inusitadas, que atingem sentidos bem mais amplos. Para demonstrar o dar-se conta da relatividade do tamanho dos objetos naquele lugar, Evangelina compara o bairro a uma imensa confeitaria e as casas, a bolos expostos, plácidos e sonolentos. As casas-bolo, com suas cores neutras e construídas em andares, se repetiam uma após a outra exaustivamente, como se estivessem em um balcáo de exposição. E essa repetiçáo exaustiva chega a despertar uma repulsa em Evangelina, como se a repetição em si fosse um pesadelo do qual não poderia se desvencilhar, em que um estado de tensão constante se instauraria, à espera do perigo, do macabro. Os gramados seriam um contraponto à verdadeira vocação do deserto, das planícies do Colorado. Exalavam artificialidade e conformismo, 
como sorrisos falsos. Os arbustos cortados em forma esférica também apontam para a artificialidade. São comparados a animais domados de circo: têm de se adequar a determinado comportamento ou formato para fazer parte daquele espetáculo de dissimulação. É esse tipo de descriçáo imagética que se realiza ao logo do romance em questão.

\section{Evangelina: concretude e afeto, vocação aquática e preenchimento deliberado da memória}

Chegamos, assim, ao ponto do que acreditamos ser o cerne da manifestação do realismo afetivo, com base do que depreendemos da evoluçáo desse conceito em Schøllhammer, em Azul corvo: os sentidos e as experiências afetados pela concretude, em especial o que chamamos de "vocação aquática" de Evangelina; o trauma que afeta o destino da protagonista; e o que consideramos como "preenchimento deliberado" da memória, um fenômeno da contemporaneidade que constatamos, em maior ou menor grau, em diversos romances dos dias de hoje, sejam eles brasileiros ou estrangeiros.

Evangelina, ao informar o fato de ter nascido em Albuquerque (Texas, EUA) e rememorar sua infância com a mãe no Rio de Janeiro, desconsidera esse nascimento factual, por não ter memória alguma desse período, e se considera nascida na praia de Copacabana: "Nasci portanto aos dois anos de idade na praia de Copacabana, e era sempre verão, mas um verão irmão da água, e minhas ferramentas para mudar o mundo, para alterá-lo e moldá-lo e torná-lo digno de mim, eram um baldinho vermelho, uma peneira, uma pá e um ancinho amarelos" (LISBOA, 2014a, p. 39). No parágrafo subsequente, continua: "E lá adiante havia um horizonte sobre o qual eu não pensava. A faixa imaginária onde o céu e o mar se dividiam, líquido para um lado, não líquido para o outro. Uma espécie de abstrato concreto" (LISBOA, 2014a, p. 39, grifos nossos). Nesses dois fragmentos residem dois aspectos importantes para a construção do romance e seu diálogo com o afetivo: a relaçáo entre a concretude e os afetos e a vocação aquática de Evangelina, que seria uma manifestação ou uma consequência dessa relação concretude/afetividade.

O princípio das percepçóes afetivas de Evangelina, como costuma acontecer, liga-se à infância, mais especificamente a essa 
infância-sempre-verão em Copacabana, com os brinquedos de praia empunhados para mudar o mundo e a água; essa infância cujas férias eram gozadas à beira do mar da Barra do Jucu em Vila Velha, Espírito Santo: "[...] eu era violentamente feliz ali, e voltava da Barra do Jucu no fim das férias com a pele da cor da madeira escura, quase como aquela mesa de jacarandá que tínhamos na sala de casa” (LISBOA, 2014a, p. 45).

Evangelina demonstra uma ligação com um universo, o aquático, que não é primordialmente o seu. Há uma espécie de sentimento de pertença a um mundo que, primitivamente, náo faz parte dela, mas que ela aceita como sendo. No romance, isso se liga diretamente à sua trajetória: Evangelina se desloca para um lugar que não é o seu, em busca de alguém que nunca viu e que é o seu pai biológico. Após toda uma sorte de idas e vindas, encontra seu lugar não com Daniel, mas com Fernando e Carlos, "acidentes de percurso" que se tornam sua família. Vejamos a seguinte citação:

Eu deixava em paz o horizonte e preferia sonhar com as ilhas, que eram reais e talvez alcançáveis a nado se um dia me dedicasse à natação e separadas por um mundo de sombras diferentes, um mundo de velocidades e sons diferentes, onde animais muito diferentes de mim existiam. O mundo dos peixes, das algas, dos moluscos, das conchas azul corvo - como as que eu leria num poema, bem mais tarde. (LISBOA, 2014a, p. 39)

Essa identificação com o aquático se vê aqui por meio de objetos e seres relacionados ao mar: "peixes", "algas", "moluscos", "conchas azul corvo". Todos eles acabam por mobilizar os afetos de Evangelina. O poema aqui aludido é "The fish" ("Os peixes"), de Marianne Moore, que na adolescência se torna "o poema" de Evangelina e cuja imagem ("conchas azul corvo") dá título ao romance. Distante de seu ambiente aquático, na secura do deserto do Colorado, Evangelina se deleita com a leitura do poema: "Quando eu lia aquele poema chamado 'The Fish', os peixes, era transportada para um mundo de cores, de movimentos primordiais. Havia nele caranguejos como lírios verdes e chapéus-de-sapo submarinos" (LISBOA, 2014a, p. 125-126). 
Notamos que o modo de construção das imagens concretas de Evangelina que remetem a seus afetos se assemelha às imagens do poema de Moore. O inusitado, como os "caranguejos como lírios verdes" e os "chapéus-de-sapo submarinos", sempre aparecerá na elaboração imagética de Evangelina, como visto no excerto sobre o subúrbio de Denver. São objetos/seres concretos deslocados de seu ambiente original e que remetem aos afetos de Evangelina, deslocada de sua origem. Entretanto, nunca é demais lembrar que esse deslocamento de Evangelina não se dá de modo involuntário: é de sua vontade ir aos Estados Unidos e resolver a questão de sua ascendência.

Há várias outras remissóes à água no discurso de Evangelina, que reforçam nossa ideia de que sua relação com a água é promotora da evocaçáo de seus afetos. Observemos mais algumas delas:

Quanto a mim, quando alguém me perguntava o que eu gostaria de ser quando crescesse só me passavam pela cabeça atividades que se desenrolassem numa faixa de areia, diante de alguma arrebentação. Vendedora de empada? (LISBOA, 2014a, p. 46-47)

O mar tem um ímã que puxa as coisas, e as pessoas, e suas sombras. Às vezes regurgita despojos. Às vezes não. (LISBOA, 2014a, p. 71)

Um dia me deparei com um verso, no fim de um poema, que dizia milhares já viveram sem amor, ninguém sem água. ${ }^{9} \mathrm{E}$ achei que aquilo fazia sentido. Achei que a poesia fazia sentido, mesmo quando não fazia, mesmo quando era um torcicolo de palavras. (LISBOA, 2014a, p. 105, grifos da autora)

O início do sentimento de pertença de Evangelina ao novo espaço, inclusive, começará em presença da água em estado sólido, que é quando ela tem seu primeiro contato com a neve:

Eu abri a boca na descida e engoli neve suficiente para promover uma espécie de autobatismo. Dali em diante eu era um deles. Era igual. Era mais uma menina acolchoada num casaco impermeável violeta, e botas pretas de borra-

9 Este poema é "First things first", de W. H. Auden. 
cha forradas com pelo sintético. [...] O casaco e as botas eram de ponta de estoque mas estavam bastante bons, embora eu achasse estranho ter todas aquelas texturas se interpondo entre a minha pele e o mundo. Eu agora existia em camadas.

$[\ldots]$

[...] E de todo modo o que importava era que agora eu era um deles, sim, análoga, comparável a, semelhante. [...] Eu também gritava, eu também levava tombos, eu também. (LISBOA, 2014a, 186-187)

Até então, Evangelina não havia encontrado pontos de contato entre sua vocação líquida e a ausência de liquidez do Colorado, a despeito das chuvas que presenciou e dos passeios à beira do rio. Mas a neve - e é relevante que a água aqui seja sólida, uma vez que fortalece ainda mais o sentido de concretude - começará a despertar nela uma identificação com o lugar, que se acentuará quando seu sotaque desaparece e quando assume o lugar de Fernando na casa depois de sua morte, ocupando o quarto que era dele e Carlos, o que era dela. Evangelina também vai trabalhar na biblioteca onde Fernando trabalhava e compra um automóvel da mesma marca do veículo de Fernando, um Saab. Além disso, também assume uma característica do pai afetivo: não é de falar muito (LISBOA, 2014a, p. 297).

Além da água, há também outros elementos concretos que se relacionam com a narração de Evangelina. Há, ao longo do romance, a presença insistente de animais (não-aquáticos) que se relacionam com as experiências de Vanja e das demais personagens e que inclusive estão presentes nos títulos de alguns capítulos. É o caso da referência à barata (primeiro capítulo, "Periplaneta americana"), da cascavel que mata o avô materno (segundo capítulo, "Crotalus atrox"), do urso cinzento que mata Timothy Treadwell (quarto capítulo, "Ursus arctos horribilis"), do costume americano de se pedir licença para acariciar o cachorro (sexto capítulo, "May I pet your dog?”), da relação lobo/cão (sétimo capítulo, "O lobo do homem"), dos corvos (oitavo capítulo, "Corvus corax, Corvus brachyrhynchos"), dos coiotes (décimo quarto capítulo, "Canis latrans"). O próprio título do romance remete a essa concretude do deslocamento de Vanja: o azul, referente à concha, 
relaciona-se com o ambiente marinho e de origem, o carioca; já o corvo seria uma remissáo ao ambiente desconhecido e posteriormente eleito, o americano, mas sem nunca perder o vínculo com o Brasil (Fernando) e o universo latino (Carlos).

À parte dessa relação do concreto que mobiliza os afetos da protagonista, observada especialmente por meio da identificação com o mundo aquático, também verificamos que o trauma sofrido por Evangelina muda seus rumos. Schøllhammer (2013) considera o trauma como um dos elementos que, ligados ao choque, também se relaciona ao afetivo. No caso de Evangelina, o trauma motivador é a morte da mãe. Suzana é acometida por uma doença incurável e, durante um passeio em que tomam sorvete, conta para a filha a única coisa que é "inteiramente previsível" e que "vai acontecer um pouco antes da hora" (LISBOA, 2014a, p. 71): sua morte. A reação de Vanja não é a de revolta, mas o de desejar ir para um outro espaço: "Vanja quer mergulhar até o fundo do mar onde os moluscos estranhos de cor estranha vivem suas vidas estranhas" (LISBOA, 2014a, p. 72). É essa a postura que escolhe para dali em diante: após a morte da mãe, fica um tempo na casa da tia adotiva, Elisa, e comunica o desejo de ir para junto de Fernando buscar o pai biológico. Vanja decide travar o que chama de "guerrilha interna": "[...] não ter pena de mim mesma, apesar de todos os diminutivos que ouvia, ao meu redor, vindos de bocas levianas - coitadinha, pobrezinha e afins" (LISBOA, 2014a, p. 74). Suzana e Vanja se prepararam para a morte. E para sair desse lugar de vítima, Vanja precisava “[...] de um nicho de quietude, de não acontecimentos, um momento duradouro, comprido, um momento que tivesse o tamanho de muitos momentos, tantos quantos fossem necessários" (LISBOA, 2014a, p. 75). Por isso decide ir aos EUA, para trabalhar o trauma que havia sofrido e não vivenciá-lo de forma vitimizada. Portanto, a perda da mãe, que coincide com outro marco de passagem, a chegada da adolescência, será fator decisivo na busca pela própria identidade da protagonista e de seu lugar no mundo.

Outro ponto que nos propusemos a expor como manifestação do realismo afetivo em Azul corvo é o que denominamos de "preenchimento deliberado" da memória. Como afirmado anteriormente, essa não é uma especificidade do romance de Lisboa. Observamos o mesmo fenômeno em romances brasileiros, como 
Nove noites (2002), de Bernardo Carvalho e Cinzas do Norte (2005), de Milton Hatoum, e estrangeiros, como Os emigrantes (1992), do alemão W. G. Sebald e $A$ marca humana (2002), do estadunidense Philip Roth. O que queremos expressar com "preenchimento deliberado" é a não necessidade de aderência da memória ao "real", ao que de fato ocorreu. A memória, como terreno do passado em contraste com o presente, não necessariamente reflete uma realidade empírica, mas uma realidade construída. Evangelina não esconde ou não utiliza pretextos para escamotear suas memórias e as memórias do outro, como a de Fernando: ela deliberadamente informa trechos de memória que não são mero resgate, mas criação, imaginação. Nesse sentido, apesar da referência a uma dose de realismo pelo retorno promovido pela rememoraçáo, a inserção dos afetos acaba por redimensionar aquilo que deveria, em tese, corresponder ao que teria ocorrido. Algumas passagens no romance em que esse preenchimento se manifesta são: a construçấo da genealogia materna; as narrativas de Fernando; a relação entre lembrança e esquecimento; a construção da genealogia paterna; a revelação da vida de Isabel. As próprias memórias e as memórias das demais personagens são momentos em que os afetos se manifestam e conduzem a imaginação de Vanja. Foquemos, pois, nas duas primeiras passagens elencadas: a genealogia materna e as narrativas de Fernando.

Sobre a ascendência materna, Evangelina informa, no segundo capítulo, que a mãe era professora de inglês e espanhol, no Texas, e de inglês, espanhol e português para estrangeiros, no Rio. Suzana perdera a mãe, Maria Gorete, aos nove anos e se mudou com o pai geólogo, Abner, para os EUA. Lá, não se sabe o porquê, rompeu laços com Abner e mudou-se para outra cidade. Assim, Vanja não tinha informaçôes mais palpáveis do avô e apenas algumas da avó. É o que a narradora afirma:

Minha mãe contava histórias sobre sua mãe. Sobre seu pai, falava apenas o indispensável.

Eu imaginava minha avó como uma mulher bem magra de pés pequeninos, que colecionava cartóes-postais de lugares com nomes sugestivos como Hannover e Islamabad. Tinha um gato que se deitava em seu colo e mordia as outras pessoas. Gato excêntrico, que preferia o uso dos 
dentes ao das garras. Um dia o gato caiu da janela do apartamento e morreu, estatelado na calçada. As pessoas diziam que o gato tinha se suicidado.

$[\ldots]$

Eu imaginava meu avô com um chapéu de caubói, vendendo seus conhecimentos de geologia para as empresas de exploração de petróleo no Texas. E um dia sendo picado por uma cascavel mortífera chamada Crotalus atrox. Ele tinha um paletó azul e uma faixa de gordura na nuca. (LISBOA, 2014a, p. 47-48)

Evangelina não tem memórias suas de seus avós maternos. Ela tem as memórias seletivas da mãe, que escolhe contar algumas histórias de Maria Gorete e um ou outro detalhe de Abner. Tanto é que utiliza o verbo "imaginar" para construir uma memória dos dois. Sobre o avô, inclusive, não se sabe se ter "um paletó azul e uma faixa de gordura na nuca" foi uma das poucas informaçóes repassadas por Suzana ou se ainda são detalhes da imaginação de Vanja. Entendemos que detalhes informados por Suzana se misturam à criação de Vanja.

Durante a adolescência de Evangelina, Fernando (Chico Ferradura) narra a ela partes de sua vida, como aquela em que participou da Guerrilha do Araguaia. Ao reconstruir as narrativas de Fernando, ela comenta sobre suas intervençóes:

Chico era bom com as armas.

Também era bom com as mulheres.

$[\ldots]$

Mais ou menos na mesma época ele se apaixonou pela primeira prostituta de sua vida, no instante exato em que ela segurou sua mão e a colocou no decote da blusa. Ele a pediu em casamento.

Ele não me disse prostituta. Definiu-a certo dia, depois de ter tomado umas cervejas, como uma moça que trabalhava numa dessas casas de moças, e a minha imaginação foi completando o resto, foi pescando os significados do silêncio dele, pendurados no ar como esses balôes de histórias em quadrinhos. Ele disse que gostou dela, e eu pensei no decote da blusa e achei que podia de fato ter sido assim, da 
mesma maneira como pensei algumas outras coisas ao longo desses anos. Afinal, se as pessoas não me forneciam detalhes, eu tinha o direito moral de providenciá-los eu mesma. (LISBOA, 2014a, p. 60-61, grifos nossos)

Nesse trecho verificamos que o movimento de Evangelina, ao providenciar ela mesma os detalhes cujo acesso lhe era vedado, seja por um motivo ou outro, era algo inerente à sua vontade. Ela se considera no "direito moral" de inventar, já que muitos eram os momentos reticentes no discurso de Suzana e Fernando, em especial. Deliberadamente, a menina recria a memória do pouco que Fernando deixa entrever em sua fala. Essa prática fica clara quando ela diz que ia "pescando os significados do silêncio dele". Evangelina interpreta a seu gosto as lacunas deixadas por Fernando. Se algo "podia de fato ser assim", então passava a ser, como a prostituta segurar a máo de Fernando e colocá-la no decote da blusa, enquanto ele a pede em casamento. Plasticamente, idealmente era algo interessante para Evangelina, que então registra a seu modo a memória do outro.

\section{Considerações finais}

O realismo afetivo de Schøllhammer, em sua evolução, é um conceito interessante para pensarmos determinadas narrativas contemporâneas. Ao entender o afetivo, em linhas gerais, como um estímulo imaginativo que promove a união de um posicionamento ético a uma determinada estética, Schøllhammer postula que essa modalidade de realismo, por meio de efeitos de realidade sensitivos, podem promover um uso extremo de concretude, fazendo com que os limites entre realidade e representação se destaquem.

Propusemo-nos a enfocar, em Azul corvo, de Adriana Lisboa, manifestaçóes do realismo afetivo por meio do questionamento entre as margens do real e da ficção que a praticamente todo momento se insinuam no romance. Buscamos ressaltar alguns redimensionamentos de realidade, em perspectiva afetiva, no discurso da protagonista. Esse destaque se deu por meio da percepção dos sentidos e das experiências de Evangelina afetados por elementos concretos, principalmente pelo que chamamos de "vocaçáo aquática"; pelo trauma da morte materna, 
que afetou o destino da menina em transição à adolescência; e o que identificamos como "preenchimento deliberado" da memória realizado por Evangelina. Dessa maneira, a narração inventiva de Vanja representa os limites borrados entre o que aconteceu de fato e o que poderia ter acontecido, entre a instituição de uma realidade e de uma ficção. Tais limites tocam na instauração de uma concretude que a todo momento dialoga com os afetos da narradora, forçando-a, em seu percurso identitário, a obedecer a outras escalas de realidade.

\section{Referências bibliográficas}

AUDEN, W. H. First things first. Disponível em: <https://www.poeticous. com/w-h-auden/first-things-first>. Acesso em: 16 fev. 2019.

BARBIERI, T. Fiç̧ão impura: prosa brasileira dos anos 70, 80 e 90. Rio de Janeiro: EdUERJ, 2003.

BERND, Z.; SOARES, T. Modos de transmissão intergeracional em romances da literatura brasileira atual. Alea, v. 18, n. 3, set-dez, 2016, p. $405-421$.

BOSI, A. Situação e formas do conto brasileiro contemporâneo. In: (org.). O conto brasileiro contemporâneo. 14 ed. São Paulo: Cultrix, 2002, p. 7-22.

BRAUCKS, N. C. M.; BARZOTTO, L. A. Romance e poesia em Azul corvo (2010), de Adriana Lisboa. Estação Literária, v. 14, dez, 2015, p. 121-134.

CANDIDO, A. Introdução. In: Formação da literatura brasileira: momentos decisivos. v. 1.8 ed. Belo Horizonte/ Rio de Janeiro: Itatiaia, 1997, p. 23-37.

. A nova narrativa. In: . A educação pela noite. 6 ed. Rio de Janeiro: Ouro sobre Azul, 2011, p. 241-260.

CARNEIRO, F. Das vanguardas ao pós-utópico: ficção brasileira no século XX. In: No país do presente: ficção brasileira no início do século XXI. Rio de Janeiro: Rocco, 2005, p. 13-34.

CARVAlHO, B. Nove noites. São Paulo: Companhia das Letras, 2013.

CASTRO, E. C. A memória, seus fios e tramas: dois livros de Adriana Lisboa - Os fios da memória e Azul corvo. Cerrados, v. 20, n. 31, 2011, p. 157-168. 
COQUEIRO, W. S. A representação da identidade feminina no mundo globalizado do século XXI: uma leitura de Azul corvo de Adriana Lisboa. Todas as musas, ano 4 , n. 2, jan-jun, 2013, p. 145-153.

DALCASTAGNÈ, R. Deslocamentos urbanos na literatura brasileira contemporânea. Brasiliana: Journal of Brazilian Studies, v. 3, n. 1, 2014, p. 31-47.

FOSTER, H. O retorno ao real. Concinnitas, ano 6, v. 1, n. 8, jul, 2005, p. 163-186.

HATOUM, M. Cinzas do Norte. São Paulo: Companhia das Letras, 2015.

IMBASCIATI, A. Afeto e representação: para uma análise dos processos cognitivos. Tradução de Neide Luzia de Rezende. São Paulo: Editora 34, 1998.

LAPLANCHE, J.; PONTALIS, J.-B. Diccionario de psicoanálisis. Tradução de Fernando Gimeno Cervantes. 6a reimp. Buenos Aires: Raidos, 2004.

LISBOA, A. Azul corvo. Rio de Janeiro: Objetiva, 2014 a.

. Crow blue. Tradução de Alison Entrekin. New York: Bloomsbury, $2014 \mathrm{~b}$.

. Biografia. Disponível em: <https://www.adrianalisboa.com/biografia>. Acesso em: 16 fev. 2019.

MOOREN, M. The fish. Disponível em: <https://www.poets.org/poetsorg/ poem/fish-1>. Acesso em: 16 fev. 2019.

PELLEGRINI, T. Uma área de sombra. In: - Gavetas vazias: ficção e política nos anos 70. São Carlos: EDUFSCar; Mercado das Letras, 1996.

RESENDE, B. A literatura brasileira na era da multiplicidade. In:

Contemporâneos: expressôes da literatura brasileira no século XXI. Rio de Janeiro: Casa da Palavra, 2008.

ROTH, P. A marca humana. Trad. Paulo Henriques Britto. São Paulo: Companhia das Letras, 2014.

SCHØLLHAMMER, K. E. À procura de um novo realismo: teses sobre a realidade em texto e imagem hoje. In: OLINTO, H. K.; SCHØLLHAMMER, K. E. (orgs.). Literatura e mídia. Rio de Janeiro: PUC-Rio; São Paulo: Loyola, 2002.

. Os novos realismos na arte e na cultura contemporâneas. In: PEREIRA, M. et al (orgs.). Comunicação, representação e práticas 
sociais. Rio de Janeiro: PUC-Rio; Aparecida, SP: Ideias \& Letras, 2004.

O realismo de novo. In: Ficção brasileira contemporânea. $2 \mathrm{a}$ ed. Rio de Janeiro: Civilização Brasileira, 2011.

- Pacto renovado com a história: o realismo contemporâneo brasileiro. Ciência Hoje. sobre Cultura. Rio de Janeiro, n. 9, jul. 2012a, p. 4-5.

. Realismo afetivo: evocar realidade além da representação. Estudos de Literatura Brasileira Contemporânea, n. 39, jan-jun, 2012b, p. 129-148.

. Realismo afetivo: evocar realidade além da representação. In:

Cena do crime: violência e realismo no Brasil contemporâneo. Rio de Janeiro: José Olympio, 2013, p. 155-185.

SCHØLLHAMMER, K. E. Crítico fala sobre realismo e violência nas artes brasileiras. [22 fev. 2014]. Rio de Janeiro: O Globo. Entrevista concedida a Guilherme Freitas.

SEBALD, W. G. Os emigrantes: quatro narrativas longas. Trad. José Marcos Macedo. São Paulo: Companhia das Letras, 2009.

Renata Rocha Ribeiro. Bacharel, mestre e doutora em Letras e Linguística (Estudos Literários) pela Universidade Federal de Goiás (UFG), onde atualmente é professora da Faculdade de Letras (FL) (Literatura Brasileira e Estágio do Português). Professora da área de Estudos Literários do Programa de Pós-Graduação em Letras e Linguística da FL/UFG. Realiza estágio pós-doutoral vinculado ao Programa de Pós-Graduação em Estudos Literários da Universidade Federal de Minas Gerais, sob supervisão da profa. Dra. Graciela Ravetti, com o projeto "Memórias da ditadura em romances de Adriana Lisboa e María Teresa Andruetto". Pesquisa, também, questôes relacionadas ao romance brasileiro contemporâneo e se interessa, além deste, pelos seguintes temas: literatura brasileira, teoria da narrativa, ensino de literatura, Osman Lins. Participou da organização das seguintes coletâneas: Inscriçôes da memória (2017); Literatura brasileira contemporânea: leituras diversas (2017); Narrativa juvenil contemporânea (no prelo); Cem anos de Tropas e boiadas (no prelo). E-mail: renatarribeiro@yahoo.com.br

Recebido em: 30/05/2018

Aceito em: 20/09/2018 